\title{
Interventional Spine Research: The Evolution of Informed Consent
}

\author{
David A. Lenrow, MD and Larry H. Chou, MD
}

The future success of the field of interventional pain medicine depends on proof of positive outcomes. Evidence based medicine has an increasing relationship to insurance reimbursement. This makes new modes of pain management dependent upon human subject research. To succeed physicians must fulfill the ethical and regulatory requirements of research, specifically informed consent. History makes clear the importance of these ethical principles. Reliance on the beneficence and ethics of investigators has failed to protect subjects. This has led to ethical codes and governmental intervention. The basis of human research regulation is the Nuremberg Code and its underlying ethical principles. This code elucidates the requirements of Understanding and Voluntariness in informed consent for research.
An analysis of these principles helps researchers fulfill the spirit of the governmental regulations and highlights the importance of protecting individual's rights. The current system of federal oversight of human research is cumbersome and inadequate. It leaves large groups of subjects unprotected and its lumbering pace often impedes investigators progress in spite of their compliance with ethical principles. Reform of these systems, is long overdue and physicians must play a role if we are to have efficient ethical human subject research in the future.

Keywords: Research Regulation, Informed Consent, Nuremberg Code, Ethics
In the current era of outcome oriented medicine and evidence based practice, the need for human subject research has become more immediate. To justify novel modes of treatment and procedures the forces are greater now than ever before to investigate their efficacy through human studies. This pressure is of particular relevance for interventional pain physicians. Third party payors may deny reimbursement for a novel interventional procedure without documented scientific evidence establishing beneficial outcomes. In view of the mounting force on physicians to produce this evidence, it is useful to review the requirements for ethical human research that provides protection for potential subjects.

These protections have developed in a piecemeal fashion by governmental responses to breaches in the ethical conduct of research. This reactionary approach by U.S. regulators has led to a poorly designed, inefficient system that

From the Department of Rehabilitation Medicine, University of Pennsylvania, Philadelphia, Pennsylvania. Dr. Lenrow is Vice Chairman of Clinical Services in the Department of Rehabilitation Medicine. Address correspondence: David Lenrow, MD, 5th floor Gates Bldg, 3400 Spruce Street, Philadelphia, PA 19104. E-mail: dlenrow@mail.med.upenn.edu often fails its intended purpose. The primary research subject protection is embodied in the doctrine of informed consent.

The legal and ethical standards for informed consent in treatment and research evolved separately in the United States. The parameters for adequate informed consent in treatment were addressed through the courts in individual lawsuits. Over time this generated a body of law with standards of disclosure and other required conduct of physicians in the realm of patient care. In the research arena, federal regulators have had the primary role as the courts played a much smaller role in the regulation of informed consent. The specific regulators involved depend on which federal agency has jurisdiction over the particular research. Federal regulation was in response to specific violations of human rights in research. The requirement of informed consent in research and how it differs from that in the treatment realm is related to the requirements of understanding and voluntariness in informed consent. (In this paper any reference to treatment refers to all interventions done within the doctor-patient relationship, including those for diagnosis.)

There has been no overriding mechanism for ensuring the adequacy of informed consent, nor any global plan by the federal government. The specific events that led to regulatory and ethical responses will be outlined, as will some 
important legal cases. The failure of the government to articulate clear requirements leaves human subject researchers with little guidance in complying with ethical research. Different standards for consent and their rationale become evident from the perspective of history, law and regulation.

\section{HISTORY}

The discussion of human medical research ethics starts with the foundation set by the Nuremberg Code. On August 15, 1947 the International Military Tribunal formulated the Nuremberg Code (1). The Nuremberg Code was made in response to the experiments that were perpetrated, in the name of science, in the Nazi concentration camps during World War II. The atrocities committed by the Nazi doctors served as the modern starting point for the medical ethics dialogue on human experimentation (2,3). Imprisoned individuals were tortured and mutilated with the endpoint often being death. Concentration camp inmates were submerged in freezing water to see how long they would survive. Subjects suffered mutilation at the hands of surgeons. People were used merely as means to an end.

These Nazi doctors believed that the goal of advancement of science justified these experiments. The result of their trial, the Doctors Trial, was the formulation of the Nuremberg Code (4). The code consists of 10 rules or the 10 commandments of ethical human research as shown in Table 1 (5). Eight of these rules address the ethics of the research project itself. They focus on the scientific validity and safety of the proposed investigation.

The two remaining rules focus on informed consent, and thereby empower the subject. They protect the subject's human rights. No longer is the subject of research at the mercy of the investigator. The investigator is given the duty, is required, to be certain that the subject is truly informed. Rule \#1 addresses the requirements of informed consent and \#9 requires that the subject have the right to terminate the experiment.

The first rule of the Nuremberg Code requires informed consent as an inviolate component of subject participation in research. "The voluntary consent of the human subject is absolutely essential."(1) The requirements are:

- Legal capacity to give consent.

- So situated so as to be able to exercise free choice.

- Sufficient knowledge and understanding.
The requirements of informed consent are outlined in Rule \#1 and then further defined. The free power of choice requires the absence of force, fraud, deceit, duress, overreaching, and other forms of constraint or coercion. Rule \#1 goes on to further describe sufficient knowledge and understanding.

In the United States violations of the Nuremberg Code occurred during and after the Doctor's Trial. Brief analyses of the notable examples are helpful in understanding the subsequent federal regulatory scheme. The Tuskegee Syphilis Study (6) was a study run by the Public Health Service (PHS) from 1932-1972. The study took place in rural Macon County Alabama, a community of poor African-Americans. The goal of the study was to observe and categorize the natural history of syphilis, to determine if the disease progressed differently in blacks and whites. The subjects were 399 black men with syphilis and 201 controls; they were never informed that this was a study. They therefore never consented to the study. In the 1940s, when penicillin became available, these men were not treated. The PHS went to great lengths to prevent the subjects from obtaining treatment. Parts of the study were published in peer reviewed medical literature and there was no objection in the medical community.

Tuskegee violated the absolute requirement of informed consent in the Nuremberg Code. From this and other studies it has been concluded that society cannot rely on those in positions of authority to act in the best interest of subjects (7). The beneficence of physicians cannot be relied on in the research arena. Physician researchers do not always respect the autonomy of their subjects. The researchers in Tuskegee used their professionalism and greater knowledge to exploit their subjects. Some members of the PHS defended the research after the press exposed the study (8). These men were living in the poor, rural, segregated south and were obedient to authority. This was the only way they could get health care. They were vulnerable and even if they consented, it would not have been voluntary.

In the Jewish Chronic Disease Hospital in Brooklyn, cancer cells were injected into twenty-two patients without their knowledge or consent (9). The patients were elderly and debilitated. The goal of the research was to see how fast they would reject the cancer cells. Physicians performed these injections on patients under an experimental protocol to advance scientific knowledge with no intention to treat the patients. This study was approved by the hospital. 


\section{Table 1. The Nuremburg Code}

Permissible Medical Experiments The great weight of the evidence before us is to the effect that certain types of medical experiments on human beings, when kept within reasonably well-defined bounds, conform to the ethics of the medical profession generally. The protagonists of the practice of human experimentation justify their views on the basis that such experiments yield results for the good of society that are unprocurable by other methods or means of study. All agree, however, that certain basic principles must be observed in order to satisfy moral, ethical and legal concepts:

1. The voluntary consent of the human subject is absolutely essential. This means that the person involved should have legal capacity to give consent; should be so situated as to be able to exercise free power of choice, without the intervention of any element of force, fraud, deceit, duress, over-reaching, or other ulterior form of constraint or coercion; and should have sufficient knowledge and comprehension of the elements of the subject matter involved as to enable him to make an understanding and enlightened decision. This latter element requires that before the acceptance of an affirmative decision by the experimental subject there should be made known to him the nature, duration, and purpose of the experiment; the method and means by which it is to be conducted; all inconveniences and hazards reasonably to be expected; and the effects upon his health or person which may possibly come from his participation in the experiment.

The duty and responsibility for ascertaining the quality of the consent rests upon each individual who initiates, directs or engages in the experiment. It is a personal duty and responsibility, which may not be delegated to another withimpunity.

2. The experiment should be such as to yield fruitful results for the good of society, unprocurable by other methods or means of study, and not random and unnecessary in nature.

3. The experiment should be so designed and based on the results of animal experimentation and a knowledge of the natural history of the disease or other problem under study that the anticipated results will justify the performance of the experiment.

4. The experiment should be so conducted as to avoid all unnecessary physical and mental suffering and injury.

5. No experiment should be conducted where there is an a priori reason to believe that death or disabling injury will occur; except, perhaps, in those experiments where the experimental physicians also serve as subjects.

6. The degree of risk to be taken should never exceed that determined by the humanitarian importance of the problem to be solved by the experiment.

7. Proper preparations should be made and adequate facilities provided to protect the experimental subject against even remote possibilities of injury, disability, or death.

8. The experiment should be conducted only by scientifically qualified persons. The highest degree of skill and care should be required through all stages of the experiment of those who conduct or engage in the experiment.

9. During the course of the experiment the human subject should be at liberty to bring the experiment to an end if he has reached the physical or mental state where continuation of the experiment seems to him to be impossible.

10. During the course of the experiment the scientist in charge must be prepared to terminate the experiment at any stage, if he has probably cause to believe, in the exercise of the good faith, superior skill and careful judgment required of him that a continuation of the experiment is likely to result in injury, disability, or death to the experimental subject.

THE NUREMBERG CODE [from Trials of War Criminals before the Nuremberg Military Tribunals under Control Council Law No. 10. Nuremberg, October 1946-April 1949. Washington, D.C.: U.S. G.P.O, 1949-1953.]

Historically prisoners have often been subject to experimentation (10). Prisoners are a captive population and represent a readily available group of subjects eager to earn whatever money they can. When consent is obtained from prisoners, can it be free and informed? This discussion occurred in the 1970's after academic and other institutions used prison populations extensively for research for many years. The ethical and legal conclusion was that prisoners could not give free and informed consent. The situation of their confinement makes it impossible for them to make a decision based on free will. Participation may ease their life in prison or they may feel obligated to partici- pate. The special benefits that accrue as a consequence of their participation in the experiments erode their ability to exercise their autonomy. There is often no other means to obtain these benefits.

The experimentation on prisoners was restricted by the Department of Health and Human Services in 1978 by the guidelines for "Protection Pertaining to Biomedical and Behavioral Research Involving Prisoners as Subjects." Ironically the opposite issue has now presented itself. Prisoners with AIDS want to be subjects in experimentation on new treatment protocols. They argue that it is the only 
way they can get these new treatments and that they should be permitted to participate in these studies. The overprotection of populations of potential subjects raises new issues of free choice.

These and many other abuses in human experimentation led to federal legislation to regulate scientific investigation. The medical profession has lobbied against this restriction and argues that investigators with ethical intentions and the beneficence of physicians will guide appropriate research $(11,12)$. Until Henry Beecher's article in 1966 human researchers were thought to be the best protectors of human rights and specifically informed consent. Beecher, a prominent anesthesiologist from Harvard, published a landmark article in the New England Journal of Medicine (11). He showed that these violations were not rare aberrations. Beecher outlined his concerns about the ethics of medical research. Twenty-two studies that violated informed consent were given as examples. He was concerned that with the push for evidence based medicine ethical errors in medical research would increase. Beecher noted that prior to general implementation of new procedures, human experimentation is required to show the benefit of the new therapies. That, in conjunction with the newly available sums of money for research from hospitals and the National Institutes of Health, could drive the violation of human research ethics.

Beecher mentions the separation of the interests of science and the interests of the patient, but does not further develop the problem. Beecher skirts the lack of informed consent by concluding that truly informed consent may not be obtainable, but that the "patient will never agree to jeopardize his health or his life for the sake of science" (11). So to protect the patient/subject, Beecher suggests investigators always strive for fully informed consent, including making it clear that they are participating in an experiment. The second safeguard, which Beecher thinks is the more reliable of the two, is "the presence of an intelligent, informed, conscientious, compassionate, responsible investigator."

Beecher did well to identify the issues at such an early stage in the race for medical advancement. The funding through federal programs including the National Institutes of Health has increased many times over since his article. Perhaps of greater concern is the current trend for increased amounts of research funding from private sources including medical device manufacturers and pharmaceutical companies.

\section{IMPORTANCE}

The requirement of informed consent prior to medical treatment or investigation allows for individual autonomy and self-determination. Subjects have a right to make decisions on their behalf. These values are fundamental in our society and government $(13,14)$. We do not believe that it is acceptable to sacrifice the rights of one individual for the benefit of others or society as a whole. This is evident throughout our law and history. The preamble of the U.S. Constitution stresses liberty. Our Constitution in the $4^{\text {th }}$ and $14^{\text {th }}$ amendments sets forth certain basic individual rights and affirms the fundamental importance of individual autonomy in our society, government and history (15). The United States Supreme Court has upheld the fundamental right of individuals to autonomy and self-determination. In cases involving abortion and the right to die, the right to self-determination and bodily integrity has repeatedly been affirmed.

In the history of the United States and in our current society, autonomy and self-determination are guiding principles. This is evident in how we regulate and in what we fund as a society. Healthcare is not a right in our society. We continue to have over 40 million uninsured Americans. The sale and manufacture of tobacco products are legal in spite of the their known ill effects on health. Dangerous sports, motorcycles and alcohol are all legal. The choice belongs to the individual. We allow individuals to make lifestyle decisions, as well as choices in whether or not to seek health care. Individuals are free to choose to undergo or refuse treatment for disease or injury even if the result is death. Autonomy and self-determination are highly valued, fundamental rights in the United States historically and by long standing tradition, as well as, under current law and practice.

The components of informed consent are defined in the Nuremberg Code and in the Belmont Report (16). This report was sponsored by the National Research Act, which focused on human subject protection. It did not adopt the Nuremberg Code but has some similarities. To give informed consent, the individual must be in a position to freely agree to the suggested course of action. In the Belmont Report the requirements of informed consent are information, comprehension and voluntary assent. This is similar to Rule \#1 of the Nuremberg Code. The requirements of understanding and voluntariness are essential to informed consent. 
To agree to a course of action requires that the implications of pursuing that action are understood. Understanding is required to be informed. Mere disclosure is not adequate to fulfill the requirement of understanding in informed consent. The recitation by the physician or researcher (or on a consent form) of a list of risks, benefits and alternatives does not satisfy understanding. This does not fulfill the ethical or legal requirements of informed consent nor does it protect the physician or researcher.

Understanding requires comprehension on the part of subjects or patients. This requires that subjects be partners in the decision. They must actively participate, and be able to manipulate the relevant information and to project what could occur as a result of their decision to participate or not. They cannot merely take the advice or suggestion of the investigator, without being brought up to the level of understanding of the investigator concerning the implications of participation in the study. This does not mean that subjects should be as conversant and knowledgeable in the science as the investigator. That would be an impossible requirement. The understanding required relates only to the implications of participation in the study. That distills down to the risks and possible benefits of participation. This is an important differentiation to keep in mind when obtaining informed consent in research.

The federal regulations do not address the process of obtaining informed consent. The Code of Federal Regulations that addresses informed consent is called the Common Rule. It does not define informed consent, but only outlines eight requirements (17). To have informed consent in research requires fully informed consent, a stricter standard than in treatment $(18,19)$. That is because in research the subject's decision is whether to participate in activities whose outcome is unknown. This uncertainty makes the requirement of fully informed consent more critical than in treatment. Moreover, the risk is not wholly for the benefit of the subject. At times there is no physical benefit to the subject. Perhaps there are intangible or moral benefits but physical and mental benefits are unproven and more unsure in research.

\section{ELEMENTS OF INFORMED CONSENT UNDERSTANDING: STANDARDS OF DISCLOSURE}

The law of informed consent in the United States has evolved separately for treatment and for research. The required disclosure for informed consent in treatment evolved in case law before any issue of informed consent in research was considered. In treatment, the beneficence of the physician initially led to limited required disclosure for informed consent. Treating physicians are believed to act in their patient's best interest. (The same cannot be said for researchers whose motivations vary.) This was called the professional standard of disclosure, or the information the average physician in the field told their patients. This kept the physician in complete control of what patients knew and therefore of the information patients used to make treatment decisions. Patients were easily manipulated and kept in the dark with respect to their options, risks and benefits. This reliance on physician beneficence left patients feeling that decisions were being made for them without their input.

This requirement for disclosure in treatment evolved in the judiciary, in many jurisdictions, to the reasonable patient standard (20). This requires that patients be given the information, which the reasonable patient, in similar circumstances, would need to make a decision regarding treatment. The Federal District Court in Canterbury reasoned that what was important to the patient was the issue, not what was important to physicians. Otherwise, physicians would remain in control, and facts important to the patient's decision could be withheld. Physicians thus could manipulate decision-making by patients and restrict their autonomy. The end point of the decision, whether consent is given or not, is in itself not the paramount issue. What is at stake is manipulation of the process intended to ensure understanding of the patient, and the consequent subversion of the individual's autonomy. The interests in the preservation of health and life do not override the individual's right to self-determination. The current standard of disclosure in treatment protects the patient's right to self-determination and is an objective standard upon which physicians can rely.

In the research realm, informed consent was initially not an issue because organized research on humans was not generally accepted. The standards of informed consent in research evolved as human subject research became accepted. Early in the development of case law any deviation from the standard practice of treatment was negligence, regardless of whether or not informed consent was obtained $(21,22)$. Later the disclosure required in research followed the common law of informed consent for treatment (23). The legal standard of disclosure for research then deviated from that in treatment. The standard became stricter. The reasoning was that the beneficence of the physician is no longer present in research. The primary goal of research is to gain scientific knowledge not to help the indi- 
vidual subject. Since the researchers interests deviate from the interests of the subject this should not be a shared decision but should be solely the subject's decision (24).

Early in the 1900's experimentation was spurned; any deviation from accepted practice put the doctor at risk (25). Cases slowly began to accept the goal of science, to advance medical knowledge. InFortner v. Koch (26) in 1935, the court notes that if there is to be progress in medicine and surgery, "there must be a certain amount of experimentation carried on; but such experiments must be done with the knowledge and consent of the patient .... and must not vary too radically from the accepted method or procedure." Later, the standard for malpractice negligence was used $(27,28)$. The amount of disclosure required was determined by the reasonable patient or the professional standard, depending on the jurisdiction's standard for required disclosure in medical treatment. Professor Jay Katz of Yale suggests that the required standard of disclosure is the full, informed consent of the reasonable subject (29).

The assumption that only medical or research experts could determine what was adequate disclosure is no longer accepted in many jurisdictions. Experts or professionals are required to determine the scientific appropriateness of the investigation but cannot determine the adequacy of disclosure to the subject (23). This change is stated in the Nuremberg Code (1), Canterbury (20) and Moore (18). In Moore, the patient underwent a splenectomy under the impression that this was solely for treatment. The cells from his spleen were used to make a cell line and monoclonal antibodies. The physician/investigator benefited economically and most likely professionally. The experimental aspects of the relationship were never disclosed to Moore. He was unaware that his tissue would be used for experimentation or that the physician had an economic interest in the procedure. The court found that there was a breech of informed consent and that the investigator had a duty to disclose all facts material to the patients consent. This included economic benefit and any personal interests of the investigator. A fiduciary duty was found in the doctor/investigator to patient/subject relationship (18).

In a Canadian case, Halushka v. University of Saskatchewan (19), a subject consented to experimentation but he was not adequately informed of the risks. He was told there was minimal risk, when the anesthetic being tested had unknown risks. The subject was informed only that a needle would go in his arm and not that he would undergo heart catheterization. The court held that the information he was given was inadequate for him to make an informed decision as to whether or not to participate in the experiment. The Halushka court elucidated the standard for disclosure in medical experimentation by differentiating research from treatment. "The subject ....is entitled to a full and frank disclosure of all the facts, probabilities and opinions which a reasonable man might be expected to consider before giving his consent." This is the reasonable subject standard of disclosure.

These sporadic tort cases on inadequate disclosure and other publicized failures of the understanding component of informed consent gave way to international codes and federal legislation. Case law on the requirements of informed consent remains sparse, and focuses on the requirement of understanding, and specifically disclosure.

\section{VOLUNTARINESS}

The second necessary component of informed consent is voluntariness. This aspect has not been discussed much by the courts. The principle flows from the rights of autonomy and self-determination. It is analogous to the law of torts and the requirement of the absence of coercion and overreaching. The Nuremberg Code stresses the voluntary requirement of informed consent, as does the Belmont Report. If a subject does not freely agree to participate in a study, informed consent cannot be obtained. Federal regulations do not address how to insure voluntary assent or absence of coercion and overreaching. We are left with little guidelines regarding implementation of this requirement. For example: Does endorsement of a study by a leading university hospital constitute undue influence?

Studies performed on prisoners (10), the mentally ill (30), the chronically ill (9) and children (31) have now been found by the courts to have violated the subject's ability to give informed consent. The subjects were exposed to coercion or overreaching. Perhaps they felt they could not refuse to participate. Their decision was not voluntary. Their particular situation or relationship to the investigator made it unreasonable to assume that they could give free and informed consent.

\section{RESPONSES: ETHICAL AND REGULATORY ETHICAL}

The response to breaches in medical research ethics began with the Nuremberg Code. It provided, for the first time, for the empowerment of the research subject, and has formed the basis for much of human research ethics, law and regulation. It ended sole reliance on the ethics of the 
researcher to determine the appropriateness of the research project and specifically their subjects' consent to participate. The requirement of informed consent is inviolate in the Nuremberg Code. There is no balancing of the benefit to society as a whole. There are no exceptions to the prerequisite of informed consent in human research. From the evidence of the Doctors Trial, it was clear to the world that society could not rely on the ethics of researchers and particularly physicians, to protect the best interest of human research subjects. The authors of the Code gave power to subjects to consent after full disclosure and to terminate the research at will. Limited disclosure or inability to give consent freely would violate the Nuremberg Code and consent would be invalid.

The World Medical Association adopted the Declaration of Helsinki in 1964 (32). In its introduction it defines the acceptable purposes of human research, as being “...to improve diagnostic, therapeutic and prophylactic procedures and the understanding of the etiology and pathogenesis of disease." The requirements for ethical research in the Declaration were similar to those set forth in the Nuremberg Code. Freely given informed consent is required. The recent revision of the Declaration of Helsinki, in October 2000, clarified the stance that placebo arms in experiments are not ethical, unless there is no accepted treatment. All individuals must get the best-known treatment. The Declaration now also requires disclosure of all relevant financial interests to the individual subject.

Why this difference in the consent requirement in research versus treatment? In research we cannot rely on the physician / investigator's beneficence and ethics. That would violate the Nuremberg Code. The distinction between research and treatment fundamentally concerns the unknown. Research involves interventions with unknown outcomes. The outcomes in treatment are accepted and known. Both medical practice and research are defined in the Belmont Report: "For the most part, the term 'practice' refers to interventions that are designed solely to enhance the wellbeing of an individual patient or client and that have a reasonable expectation of success. The purpose of medical or behavioral practice is to provide diagnosis, preventive treatment or therapy to particular individuals...The term 'research' designates an activity designed to test an hypothesis, permit conclusions to be drawn, and thereby to develop or contribute to generalizable knowledge (expressed, for example, in theories, principles, and statements of relationships). Research is usually described in formal protocol that sets forth an objective and a set of procedures designed to reach that objective."(16) Whether thera- peutic research or pure non-therapeutic research, the benefit to the subject is unknown and the requirement of maintaining the subject's autonomy is fundamental. Again, informed consent becomes an inviolate requirement in human research.

Research has been further described as a rigid protocol for the advancement of knowledge and the potential benefit of society at large. The protocol is not variable for the individual needs of subjects (33). This is in contrast to treatment, where the intervention is tailored to the individual patient's best interest. If the initial action proves not to benefit the individual, then the physician reassesses the treatment and changes course. The best interest of the patient directs the suggested treatment. The doctor-patient relationship is analogous to the fiduciary relationship established by law. In research, particularly protocol driven research, the individual is treated as part of a larger group. The assignment of subjects to protocols is not directed by the subjects' best interest. For the most part it cannot be altered if there is a suggestion that another course might be better. The constraints of research are much more rigid than those of treatment. This gives rise to the conflict between the individual patient's best interests and the interests of science.

Physicians who participate in clinical trials run by industry are aware that these are experiments and not proven therapies, that is the reason for the study. The physician acting alone who tries a novel treatment for a particular ailment, with no other intentions but to cure the patient, is the exception to the rule. The ethical guidelines of the American Medical Association stipulate that research on human subjects must be organized and protocol driven, so that valid scientific results can be obtained (34). Novel treatments by individual physicians without a protocol would fail this test; they would not qualify as research. The distinction between treatment and research remains important.

\section{REGULATORY}

There was little regulation of research ethics until 1962. The responsibility for research regulation and ethics rested with research institutions and investigators. The professional standard of disclosure for research was analogous to the standard of informed consent for treatment prevalent at that time. The beneficence of physicians was assumed to carry over into the realm of research. Society continued to rely on the professionalism of physicians to protect the autonomy, health, and well being of the indi- 
vidual subjects of human research. No guidelines existed to resolve the conflict between the goals of research and the interests of individual subjects. The subject's free will was subordinated to the cause of science. The multiple, infamous transgressions of individual autonomy, in the name of research, had yet to move the federal government into action. Interestingly, beginning in the 1940's, the Department of Defense and the Atomic Energy Commission devoted time and effort to discuss the ethics of experimentation (35). The Armed Forces Medical Policy Council adopted the principles of human research ethics from the Nuremberg Code in 1952 as guidelines for research into atomic, biologic and chemical warfare (24). Regulation of other research had yet to evolve.

The debate over regulation of research grew as violations of research ethics were disclosed to the public by the press. The first step in regulating research was in 1953 with the opening of the Clinical Center of the National Institutes of Health (NIH) (36). This set up loose guidelines for subject consent, but they only applied to research done in the Clinical Center and not to outside research funded by the NIH (37). The requirements were very limited applying only to research with an unusual hazard and to volunteers with no possibility of benefit (38). This regulation did not apply to patients. In 1962, the FDA began regulating clinical drug investigations, requiring proof of therapeutic efficacy in addition to safety (39). The FDA regulations applied to new drugs and to investigational devices, regardless of the funding source.

In 1966, the NIH, under the Public Health Service, issued a statement requiring prospective review of all proposed research funded by the Department of Health Education and Welfare (40). These rules were codified into federal regulations, with the most recent significant revision in 1991 (41). As noted earlier, these regulations are often referred to as the Common Rule. They require prospective evaluation of proposed human research by local Institutional Review Boards (IRB). All research funded by federal agencies is governed by the Common Rule (42). This is in distinction to the FDA regulation, which is applied broadly without regard for funding source, but only to investigational drugs and devices (43). The rules applied by the FDA are essentially the same as the Common Rule.

The role of these IRBs is to decentralize the control of research project oversight. In theory, they are designed to protect the subject's rights and autonomy. In practice they are composed of members primarily from the institution performing the research. This creates issues of objectivity and compliance with the disclosure of consent. The Common Rule requires that IRBs have a minimum of five members, only one of whom must be from outside the parent institution (44). The section of the Common Rule on informed consent does not define informed consent nor describe the process of obtaining consent (17).

There are several exceptions to the requirement of informed consent in the Common Rule. They are set forth in 45 C.F.R. $§ 46.116$, part d, as follows:

1. Minimal risk to the subjects

2. The waiver or alteration of informed consent will not affect the rights and welfare of the subjects.

3. The research cannot be performed without the waiver of informed consent.

These exceptions all erode the protections of the Nuremberg Code.

\section{CONCLUSION}

The federal regulation of research serves to protect the institutions conducting the research, perhaps more than the subjects. The IRBs are not required to supervise consent, nor are there any guidelines for the process of obtaining consent. The legislation is very vague in its description of informed consent. It provides only that the circumstances of obtaining informed consent must give the subject sufficient opportunity to consider whether or not to assent and must minimize the possibility of coercion and undue influence (17). There is no clarification of what the process entails, nor are there guidelines for IRBs to use to evaluate for compliance. Consequently, the requirements for informed consent of understanding and voluntariness are not adequately addressed in the current federal legislation. The only guidelines provided to ensure that consent is voluntary are the very general ones set forth above. Investigators and IRBs are left on their own to determine what is necessary to comply.

The current system of regulation was made in response to specific episodes of violation of subjects' rights. They vary by federal institution and are not applied to all research. The National Bioethics Advisory Commission's draft policy refers to the current scheme as "cobbled" (45). This has made the current system of human research regulation unwieldy, expensive and, at times, ineffective. It is important to take note that not all research is covered by the combined federal regulation of the FDA and the Com- 
mon Rule via Health and Human Services (HHS). The FDA only regulates human research involving investigational devices and drugs that are not approved. The Common Rule only applies to federally funded research. This leaves a large portion of human research outside the regulation of the federal government. All privately funded research not involving investigational drugs or devices is beyond the reach of our current scheme of human subject protections.

The approach we have taken to protect subject's rights has been a response to abuses of these rights. This has not only left out large groups of studies but it has also failed to measure up to the ideals of the Nuremberg Code or the judicial standard of disclosure in research. The change in research funding along with the push for evidence-based medicine has made these gaps in protection become craters. To have viable, ethical human research requires clear ethical rules that are implemented through an organized uniform structure. The burden on researchers should not be overwhelming nor should individual rights be compromised. That requires formulating a theoretical fact- based model and not a reactionary system of regulation. In Part II of this series the specific failures of the current protections of human subjects will be examined.

\section{REFERENCES}

1. International Military Tribunal. Trials of War Criminals before the Nuremberg Military Tribunals under Control Council Law no. 10. Government Printing Office, Washington, D.C., 1950.

2. M.A. Grodin, G.J. Annas. Legacies of Nuremberg: Medical Ethics and Human Rights. JAMA 1996; 276:1682-1683.

3. Katz J. The Consent Principle of the Nuremberg Code: It's Significance Then and Now. In Annas GJ, Grodin MA (eds). The Nazi Doctors and the Nuremberg Code: Human Rights In Human Experimentation. Oxford University Press, New York, 1992, pp 227-239.

4. United States v. Karl Brandt et al. (case 1). National Archives, Washington, D.C., November 21, 1946-August 20, 1947.

5. Shuster E. Fifty Years Later: The Significance of the Nuremberg Code. NEngl JMed 1997; 337: 1436-1440.

6. Jones JH. Bad Blood: The Tuskegee Syphilis Experiment. Free Press, New York (1981).

7. King P. Race Justice And Research. In Kahn P, Mastroianni A, Sugarman J (eds). Beyond Consent: Seeking Justice In Research. Oxford University Press, New York, 1998, pp 88-110.

8. Brandt AM. Racism and Research; The Case of the Tuskegee Syphilis Study.Hasting Center Report 1978;
8:21-29.

9. Hyman v. Jewish Chronic Disease Hosp., 248 N.Y.S.2d 245 (N.Y. Sup. Ct. 1964).

10. Hornblum AM. Acres of Skin: Human Experiments at Holmesburg Prison. Routledge, New York, 1998.

11. Beecher HK. Ethics and Clinical Research. N Engl J Med 1966; 274:1354-1360.

12. Ingelfinger FJ. Informed but Uneducated Consent. N Engl J Med 1972; 87:465-466.

13. Blackstone W. Commentaries on the Laws of England. $4^{\text {th }}$ ed. Clarendon Press, Oxford, 1770, p125.

14. Desaulniers KA. Legislation to Protect the Decisionally Incapacitated Individual's Participation in Medical Research: Safety Net or Trap Door? Regent U. L. Rev 2000-2001; 13:179,215.

$15 . \quad$ U.S. Const. amend. IV, XIV.

16. National Commission for the Protection of Human Subjects of Biomedical and Behavioral Research, the belmont report: Ethical Principles and Guidelines for the Protection of Human Subjects of Research 3 (1979). 44 Fed. Reg. 23192 (1979).

17. $\quad 45$ C.F.R. $\$ 46.116$ (2001).

18. Moore v. Regents of the University of California, 793 P.2d 479 (Cal. 1990).

19. Halushka v. University of Saskatchewan, 52 W.W.R. 608 (Sask. Ct. of Appeals 1965).

20. Canterbury v. Spence, 464 F.2d 772 (D.C. Cir. 1972).

21. Carpenter v. Blake, 60 Barb. 488, 524 (N.Y. Sup. Ct. 1871).

22. Jackson v. Burnham, 20 Colo. 532, (1895).

23. Goldner JA. An Overview of Legal Controls on $\mathrm{Hu}-$ man Experimentation and the Regulatory Implications of Taking Professor Katz Seriously. St.Louis L.J. 1993; 38: $63,71-87$.

24. Morin K. The Standard of Disclosure in Human Subject Experimentation. J Leg Med. 1998; 19:157, 221.

25. Rosoff AJ. Informed Consent: A Guide For Health Care Providers. Aspen Publishers, London, 1981.

26. Fortner v. Koch, 272 Mich. 273 (1935).

27. Karp v. Cooly, 493 F.2d 408 (5th Cir. 1974).

28. Gaston v. Hunter, 121 Ariz. 33, 57 (1978).

29. Katz J. Human Experimentation and Human Rights. St. Louis U. L.J. 1993; 38:7.

30. Barrett v. United States, 798 F.2d 565 (1986).

31. Katz J. Experimentation with Human Beings. New York, Russell Sage Foundation, 1972.

32. World Medical Association, Declaration of Helsinki: Recommendations Guiding Medical Doctors in Biomedical Research Involving Human Subjects, as adopted by the $18^{\text {th }}$ World Medical Assembly, Helsinki, Finland (1964).

33. Miller M. Phase I Cancer Trials: A Collusion of Misunderstanding. Hastings Center Report 2000; 30:3442.

34. The AMA Ethical Guidelines $§ 2.07 \underline{\text { http:// }}$ www.ama-assn.org 
35. Advisory Committee on Human Radiation Experiment, Final Report of The Advisory Committee on Human Radiation Experiment (1996).

36. Frankel MS. The Development of Policy Guidelines Governing Human Experimentation in the United States: A Case Study of Public Policy-Making for Science and Technology. Ethics in Science and Medicine 1975; 2:43-59.

37. Curran WJ. Governmental Regulation of the Use of Human Subjects in Medical Research: the Approach of Two Federal Agencies. In Freund PA (ed). Experimentation With Human Subjects. BrazillerGeorgeInc, New York, 1970.

38. Appelbaum PS, Lidz CW, Meisel A.Informed Consent: Legal Theory And Clinical Practice. New York,
Oxford University Press, 1987, p 216.

39. Drug Industry Act of 1962, 108 Cong. Rec. 17395-9 (1962).

40. Maloney DM. Protection of Human Research Subjects: A Practical Guide to Federal Laws and Regulations. Plenum Press, New York, 1984.

41. $\quad 45$ C.F.R. $\$ 46$ (2001).

42. $\quad 45$ C.F.R. $\$ 46.101(2001)$.

43. 21 C.F.R. $\$ 50$ (2001).

44. $\quad 45$ C.F.R. $§ 46.107$ (2001).

45. Policy Issues in Research Involving Human Participants, National Bioethics Advisory Commission, December 19, 2000, Draft Report for Public Comment, Government Printing Office, Washington D.C. 